\title{
Pseudomonas aeruginosa mediated apoptosis requires the ADP-ribosylating activity of ExoS
}

\author{
Melissa R. Kaufman, ${ }^{1}$ Jinghua Jia, ${ }^{1,2}$ Lin Zeng, ${ }^{1,2}$ Unhwan $\mathrm{Ha},{ }^{1,2}$ \\ Marie Chow ${ }^{1}$ and Shouguang $\operatorname{Jin}^{1,2}$
}

Author for correspondence: Shouguang Jin. Tel: +1 352392 8323. Fax: +1 3523923133. e-mail: sjin@mgm.ufl.edu

\author{
1 Department of \\ Microbiology and \\ Immunology, University of \\ Arkansas for Medical \\ Sciences, Little Rock, \\ AR 72205, USA \\ 2 Department of Molecular \\ Genetics and Microbiology, \\ PO Box 100266, University \\ of Florida, Gainesville, \\ FL 32610, USA
}

\begin{abstract}
Pseudomonas aeruginosa is an opportunistic bacterial pathogen that primarily infects immunocompromised individuals and patients with cystic fibrosis. Using a tissue culture system, invasive strains of $\boldsymbol{P}$. aeruginosa were discovered to induce apoptosis at high frequency in HeLa and other epithelial and fibroblast cell lines. This apoptotic phenotype in the infected cells was determined by several criteria including (i) visual changes in cell morphology, (ii) induction of chromatin condensation and nuclear marginalization, (iii) the presence of a high percentage of cells with subG1 DNA content, and (iv) activation of caspase-3 activity. Induction of the type III secretion machinery, but not invasion of $P$. aeruginosa is required for induction of apoptosis. The apoptosis phenotype is independent of the cytoskeletal rearrangements that occur in the host cell early after infection. Mutants in $P$. aeruginosa exoS fail to induce apoptosis and complementation with wild-type exoS restored the apoptosis-inducing capacity, demonstrating that ExOS is the effector molecule. Analysis of exoS activity mutants shows that the ADP-ribosylating capacity of Exos is essential for inducing the apoptotic pathway.
\end{abstract}

Keywords: ExoS, apoptosis, type III secretion, ADP-ribosylation

\section{INTRODUCTION}

The opportunistic bacterial pathogen Pseudomonas aeruginosa causes devastating human infections in patients with cystic fibrosis, burns and/or immunosuppression (Tummler \& Kiewitz, 1999; Salyers \& Whitt, 1994). To successfully colonize and maintain an infectious cycle the organism carefully orchestrates production of a suite of virulence determinants including pili (Hahn, 1997; Wall \& Kaiser, 1999) and non-pilus adhesins (Simpson et al., 1995), extracellular enzymes (Ohman et al., 1980; Salyers \& Whitt, 1994), and exotoxins (Iglewski \& Kabat, 1975). Some virulence factors are produced and secreted directly into the host cell using the cell-contact-mediated type III secretion machinery. To date, four such factors have been characterized, including ADP-ribosylating enzymes ExoS and ExoT (Frank, 1997; Frithz-Lindsten et al., 1997; Yahr et al., 1996a), an acute cytolytic factor ExoU (Finck-Barbancon et al., 1997; Hauser et al., 1998) and

Abbreviations: $\mathrm{FCS}$, foetal calf serum; p.i., post infection; PI, propidium iodide; TNF $\alpha$, tumour necrosis factor $\alpha$. an adenylate cyclase ExoY (Yahr et al., 1998). Expression of these secreted effector molecules as well as components of the type III secretory apparatus are under the control of the transcriptional activator, ExsA (Hovey \& Frank, 1995).

From a survey of various clinical isolates, Fleiszig et al. (1997) have divided isolates of $P$. aeruginosa into two categories, invasive and noninvasive strains, based on their abilities to invade mammalian cells. The phenotypes of these two classes are associated with the spectrum of virulence factors that are encoded within their genomes. Both types of strains harbour exoT. Typical invasive strains harbour exoS whereas noninvasive (i.e. cytolytic) strains harbour exoU. The cytolytic phenotype associated with noninvasive strains results mainly from the action of the exoU gene product (Finck-Barbancon et al., 1997; Hauser et al., 1998). Although the factor(s) for the invasive phenotype is not clearly understood, Cowell et al. (2000) have recently shown that both ExoS and ExoT have an invasioninhibitory effect on cytolytic $P$. aeruginosa strains. Despite extensive characterization of these factors including their abilities to cause morphological changes on various tissue culture cells (Finck-Barbancon et al., 
Table 1. Bacterial strains and plasmids

\begin{tabular}{|c|c|c|}
\hline Strain or plasmid & Description & Source or reference \\
\hline \multicolumn{3}{|l|}{ Escherichia coli strains } \\
\hline DH $5 \alpha$ & $\begin{array}{l}\mathrm{F}^{-} \phi 80 \text { slacZ } \mathrm{M} \text { M15 endA1 recA1 } \\
\left.\text { hsdR17( } \mathrm{r}_{\mathrm{k}}^{-} \mathrm{m}_{\mathrm{k}}^{+}\right) \text {supE44 thi-1 relA1 } \\
\Delta(\text { lacZYA-argF }) \text { U169 gyrA96 deo } \mathrm{R}\end{array}$ & Hanahan (1983) \\
\hline SE5000 & $\begin{array}{l}\operatorname{araD139} \Delta(\operatorname{argF}-\mathrm{lac}) U 169 \operatorname{rpsL150}\left(\mathrm{Str}^{\mathrm{R}}\right) \\
\quad \text { relA1 fibB } 5301 \text { deoC1 ptsF25 rbsR recA56 }\end{array}$ & Gherardini et al. (1990) \\
\hline \multicolumn{3}{|l|}{ P. aeruginosa strains } \\
\hline PAK & Laboratory strain (invasive) & D. Bradley* \\
\hline $\mathrm{PAKexs} A:: \Omega$ & exsA knockout mutant derivative of PAK & Yahr et al. (1997) \\
\hline $\operatorname{PAKexoS::\Omega }$ & exoS knockout mutant derivative of PAK & This study \\
\hline PAKexoT::Gem & exoT knockout mutant derivative of PAK & This study \\
\hline PAKexoS: : $\Omega /$ exoT: :Gem & $\begin{array}{l}\text { exoS exoT double mutant derivative of } \\
\text { PAK }\end{array}$ & This study \\
\hline 388 & Laboratory strain (invasive) & Iglewski et al. (1978) \\
\hline $388 \mathrm{exoS}:: T c$ & exoS knockout mutant derivative of 388 & Kulich et al. (1995) \\
\hline 388exoT::Tc & exoT knockout mutant derivative of 388 & Yahr et al. (1996a) \\
\hline PAO1 & Laboratory strain (invasive) & Holloway et al. (1979) \\
\hline PA103 & $\begin{array}{l}\text { Laboratory strain (non-invasive and } \\
\text { cytotoxic) }\end{array}$ & Liu $(1966)$ \\
\hline $\mathrm{PA} 103 \Delta \mathrm{exoU} / \mathrm{exo} T:: T c$ & exoU exoT mutant derivative of PA103 & Vallis et al. (1999) \\
\hline \multicolumn{3}{|l|}{ Plasmids } \\
\hline pDN18 & Broad-host-range plasmid, IncP, $\mathrm{Tc}^{\mathrm{r}}$ & Nunn et al. (1990) \\
\hline pDN19 & Broad-host-range plasmid, IncP, $\mathrm{Tc}^{\mathrm{r}}$ & Nunn et al. (1990) \\
\hline pPC110 & Gentamicin cassette in pUC7, $\mathrm{Ap}^{\mathrm{r}} \mathrm{Gen}^{\mathrm{r}}$ & Nunn et al. (1990) \\
\hline pUC19 $\Omega$ & pUC19 with $\Omega$ insertion & Totten \& Lory $(1990)$ \\
\hline pHW9945 & exoS from PAK cloned into pCR2.1-TOPO & This study \\
\hline pHW9950 & $\begin{array}{l}\text { exoS in pHW9945 disrupted by an } \Omega \\
\text { insertion }\end{array}$ & This study \\
\hline pHW9946 & exoT from PAK cloned into pCR2.1-TOPO & This study \\
\hline pHW9951 & $\begin{array}{l}\text { exoT in pHW9946 disrupted by a } \\
\text { gentamicin-resistance cassette }\end{array}$ & This study \\
\hline pHW9948 & exoS of PAK cloned in pDN19, $\mathrm{Tc}^{\mathrm{r}}$ & This study \\
\hline pHW9949 & exoT of PAK cloned in $\mathrm{pDN} 18, \mathrm{Tc}^{\mathrm{r}}$ & This study \\
\hline pUCP18 & Broad-host-range cloning vector, IncP, $\mathrm{Ap}^{\mathrm{r}}$ & Vallis et al. (1999) \\
\hline pUCPG18 & $\begin{array}{l}\text { pUCP18 with gentamicin selection marker, } \\
\operatorname{Ap}^{\mathrm{r}} \mathrm{Gen}^{\mathrm{r}}\end{array}$ & This study \\
\hline pUCPexos & $\begin{array}{l}\text { exoS from strain } 388 \text { cloned into pUCP18, } \\
\operatorname{Ap}^{\mathrm{r}}\end{array}$ & Vallis et al. (1999) \\
\hline pUCPGexos & $\begin{array}{l}\text { pUCPexoS with gentamicin selection } \\
\text { marker, } \text { Ap }^{r} G^{r}\end{array}$ & This study \\
\hline pUCPexoSE381A & $\begin{array}{l}\text { exoS of pUCPexoS mutated into E381A, } \\
\mathrm{Ap}^{\mathrm{r}}\end{array}$ & Vallis et al. (1999) \\
\hline pUCPGexoSE381A & $\begin{array}{l}\text { pUCPexoSE381A with gentamicin selection } \\
\text { marker, } \operatorname{Ap}^{r} G^{r}{ }^{r}\end{array}$ & This study \\
\hline pUCPexoT & $\begin{array}{l}\text { exoT from strain } 388 \text { cloned into of } \\
\text { pUCP18, } A^{r}\end{array}$ & Vallis et al. (1999) \\
\hline pUCPGexoT & $\begin{array}{l}\text { pUCPexoT with gentamicin selection } \\
\text { marker, } \mathrm{Ap}^{\mathrm{r}}, \mathrm{Gen}^{\mathrm{r}}\end{array}$ & This study \\
\hline
\end{tabular}

* Faculty of Medicine, Memorial University of Newfoundland, A1B 3V6 Canada.

1997; Hauser et al., 1998; Yahr et al., 1998; McGuffie et al. 1999; Vallis et al., 1999), the mechanisms by which these virulence factors alter mammalian cell physiology remain enigmatic.
While investigating bacterial genes that are stringently induced during infection of tissue culture cells, we noted that invasive strains of $P$. aeruginosa produce cellcontact-dependent factors that induce an apoptosis-like 
morphology in cultured cells. Further characterization of this phenotype demonstrated that the ADPribosylating activity of ExoS is required for induction of programmed cell death by invasive $P$. aeruginosa.

\section{METHODS}

Bacterial strains and plasmids. Bacterial cultures were grown in Luria-Bertani broth (L-broth) at $37^{\circ} \mathrm{C}$. Strains and plasmids used in this study are listed in Table 1 . The type III regulatory mutant PAKexsA:: $\Omega$ (Yahr et al., 1997), and the exoS and exoT mutant strains of 388 have been described previously (Kulich et al., 1995; Yahr et al., 1996b). The exoS, exoSE381A and exoT clones of strain 388 were derived from pUCPexoS, pUCPexoSE381A and pUCPexoT, respectively (Vallis et al., 1999), by inserting a $1.6 \mathrm{~kb}$ EcoRI fragment containing the gentamicin-resistance cassette from pPC110 (Nunn et al., 1990) into HindIII sites, resulting in pUCPGexoS, pUCPGexoSE381A and pUCPGexoT, respectively. The corresponding vector control pUCPG18 was generated by inserting the gentamicin cassette into the EcoRI site of pUCP18.

The exoS and exoT genes were PCR amplified from the PAK chromosome using the following two pairs of primers: exoS1, 5'-CAG TTG TTC GAG TTG ATG GTG GAT CTG GGC CCT GT-3' and exoS-2, 5'-CGT TTC GTC GCC TGG ACC TAC CTC GAC AAG AAG CA - $3^{\prime}$, and exoT-1 5'-AGG AAG GTC ATC AGC AGG GCG ATC TCG GTG GTC AT-3' and exoT-2 5'-GCT GTA CGG CGC AAA TGA AAA CGG ACA CCC CTT GG-3', respectively. Cloned exoS and exoT genes in pCR2.1-TOPO (pHW9945 and pHW9946) were disrupted by insertion of the $\Omega$ cassette (resistant to streptomycin and spectinomycin) or gentamicin-resistance cassette, respectively, to generate pHW9950 and pHW9951. Linearized plasmid DNA containing the disrupted genes were double crossed into the chromosome of PAK by electroporation to gen-

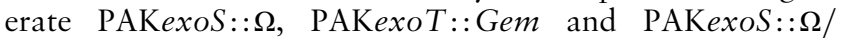
exoT::Gem mutant strains. The mutant strains were confirmed by Southern hybridization as well as by defects in ExoS and/or ExoT secretion into the medium under low-calcium type III inducing conditions (Yahr et al., 1997). Briefly, overnight bacterial cultures in L-broth containing $5 \mathrm{mM}$ EGTA were diluted 10-fold into fresh L-broth containing $5 \mathrm{mM}$ EGTA. The cultures were shaken at $37^{\circ} \mathrm{C}$ for $6 \mathrm{~h}$ and culture supernatants were recovered by centrifugation. Culture supernatants $(0.5 \mathrm{ml})$ were concentrated down to $10 \mu \mathrm{l}$ using Centricon-50, mixed with an equal volume $2 \times$ loading buffer, boiled and subjected to $10 \%$ SDS-PAGE analysis. Protein bands were visualized after staining with Coomassie blue.

Cells and media. HeLa S3 cell line in suspension culture was maintained in Jokliks modified minimal essential medium supplemented with $100 \mu \mathrm{g}$ penicillin $\mathrm{ml}^{-1}, 100 \mu \mathrm{g}$ streptomycin $\mathrm{ml}^{-1}$ and $7 \cdot 5 \%$ horse serum (MEM $+7 \% \mathrm{HS}$; Gibco). For the bacterial infections, HeLa monolayers were plated from suspension culture on the previous day. HeLa cell monolayers were maintained in Dulbecco's modified medium supplemented with $5 \%$ foetal calf serum (DMEM $+5 \%$ FCS; Gibco). All other cell lines were maintained as monolayers in DMEM $+10 \%$ FCS.

Cell infection by Pseudomonas. Overnight bacterial cultures were pelleted and resuspended in DMEM. Cell monolayers were grown to $>80 \%$ confluency in 6 -well plates $\left(\sim 5 \times 10^{5}\right.$ cells per $35 \mathrm{~mm}$ well) and washed with PBS. The cell monolayer was inoculated with $1 \times 10^{7}$ bacteria resuspended in $1 \mathrm{ml} \mathrm{DMEM} \mathrm{(m.o.i.} \mathrm{=} \mathrm{20)} \mathrm{and} \mathrm{incubated} \mathrm{for} 2 \mathrm{~h}$ at $37^{\circ} \mathrm{C}$ in a $5 \% \mathrm{CO}_{2}$ incubator. The bacterial inoculum was removed, cells were washed with PBS and fresh DMEM $+5 \%$ FCS supplemented with $200-400 \mu \mathrm{g}$ gentamicin $\mathrm{ml}^{-1}$ was added to the monolayer. Cells were incubated in $5 \% \mathrm{CO}_{2}$ at $37^{\circ} \mathrm{C}$ for an additional 3-24 h. As positive controls for apoptosis, HeLa cells were incubated with $10 \mathrm{ng}$ tumour necrosis factor $\alpha$ $(\mathrm{TNF} \alpha) \mathrm{ml}^{-1}$ plus $20 \mu \mathrm{g}$ cycloheximide $\mathrm{ml}^{-1}$.

Bacterial invasion tests. Cell monolayers were infected by the bacteria for $2 \mathrm{~h}$ and washed once with phosphate buffered saline. Subsequently, cells were grown for an additional $2 \mathrm{~h}$ in fresh DMEM + $5 \%$ FCS supplemented with $400 \mu$ g gentamicin $\mathrm{ml}^{-1}$ or $400 \mu \mathrm{g}$ amikacin $\mathrm{ml}^{-1}$ to kill extracellular organisms. Cells were harvested by scraping and lysed with $0 \cdot 1 \%$ Triton X-100 prior to serial dilution and plating on L-agar plates with appropriate antibiotics to obtain colony counts. Tests were performed in triplicate and the mean of three trials is reported. To inhibit invasion, the cell monolayers were incubated with the cytoskeletal poison cytochalasin $\mathrm{D}(10 \mu \mathrm{M})$ or the tyrosine kinase inhibitor genestein $(200 \mu \mathrm{M})$ for $2 \mathrm{~h}$ prior to the addition of bacteria.

\section{Apoptosis assays.}

Caspase-3 assay. Caspase- 3 activities were measured using a commercially available kit (Caspase- 3 cellular activity assay kit plus; BioMol). HeLa cells $\left(3 \times 10^{7}\right)$ were infected with $P$. aeruginosa, then cells were washed and harvested by scraping and centrifugation $(1000 \mathrm{~g}, 10 \mathrm{~min})$ at various times postinfection (p.i.). HeLa cells were lysed with $0 \cdot 1 \%$ Tween 20 and cell lysates (supernatants) were saved following centrifugation at $10000 \mathrm{~g}$ for $10 \mathrm{~min}$. Dilutions of the cell lysates in a 96 -well plate were incubated with the DEVD-pNA substrate, or the substrate plus caspase-3 inhibitor (supplied with the assay kit). Changes in $\mathrm{OD}_{405}$ were followed for $2 \mathrm{~h}$ at $10 \mathrm{~min}$ intervals. Protein concentration was determined using the BioRad Protein Assay System. The specific activity is reported as pmol substrate cleaved $\min ^{-1}$ ( $\mu$ g protein $)^{-1}$.

Hoechst staining of condensed chromatin. Infected cells were recovered at $20 \mathrm{~h}$ p.i. by trypsinization of the cell monolayer. Cells were washed once with PBS and stained with Hoechst $33258\left(1 \mathrm{mg} \mathrm{ml}^{-1}\right)$ for $10 \mathrm{~min}$ in the dark. Chromatin condensation was examined under the fluorescence microscope using a DAPI filter.

Flow cytometry analyses of subG1 DNA populations. Bacterial infected cells were harvested at $24 \mathrm{~h}$ p.i. by trypsinization of the cell monolayers and fixation overnight at $4{ }^{\circ} \mathrm{C}$ in $70 \%$ ethanol. Cells were harvested by centrifugation and stained for $30 \mathrm{~min}$ in $500 \mu \mathrm{l}$ propidium iodide (PI) staining solution $\left(0 \cdot 1 \%\right.$ BSA, $0 \cdot 1 \%$ RNase, $\left.0.5 \mathrm{mg} \mathrm{PI} \mathrm{ml}^{-1}\right)$. Cells were directly counted in batches of 10000 and shown by plotting PI fluorescence versus cell number. The percentage of apoptotic cells was calculated using the internal software system of the flow cytometer.

\section{RESULTS}

\section{P. aeruginosa PAK induces apoptosis in cell cultures}

PAK is an invasive strain of $P$. aeruginosa (Fleiszig et al., 1997). Infection of HeLa S3 cells by this strain was studied as an in vitro model system of bacterial-host interactions. Cultured cell monolayers were infected with wild-type PAK and subsequently followed to 

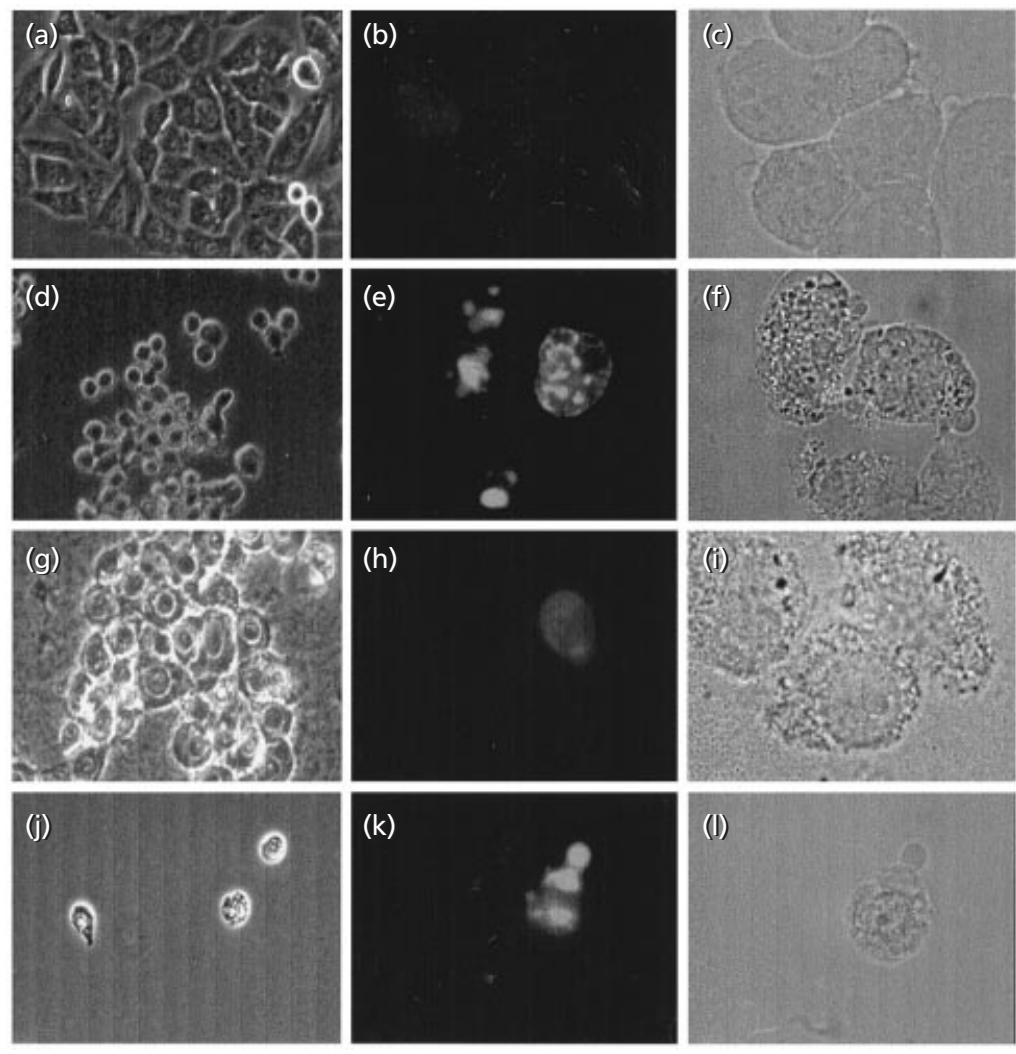

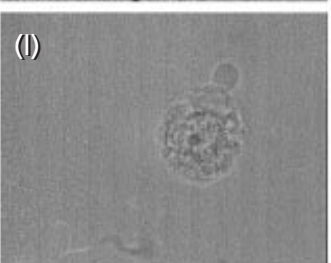

Fig. 1. Morphology and Hoescht staining of HeLa cell line S3 infected with $P$. aeruginosa. HeLa cells were incubated with no bacteria ( $a, b$ and $c), \operatorname{PAK}(d, e$ and $f), \operatorname{PA103}(g, h$ and $i)$, or TNF $\alpha$ plus cycloheximide ( $j, k$ and I). Images in the first column (a, d, $g$ and $j$ ) were captured at $3 \mathrm{~h}$ p.i., whereas remaining (second and third columns) images were at $24 \mathrm{~h}$ p.i. with 10-fold higher magnification than the first column. Cells were stained with Hoescht 33258 and viewed under fluorescent light $(b, e, h$ and k) or identical view under regular light (c, $f$, i and I) are shown. Panels (a), (d), (g) and (j) were viewed under natural light with no staining. characterize any infection-specific morphological changes. By 3 h p.i., the HeLa cells adopted a rounded morphology and subsequently detached from the monolayer (Fig. 1d). By 24 h p.i., the cells displayed a typical apoptotic morphology as determined by membrane blebbing, cell shrinkage and the presence of apoptotic bodies (Fig. 1f) as compared to uninfected controls (Fig. 1a, c).

To confirm that this morphological alteration was due to programmed cell death, a number of apoptosisspecific assays were performed. Caspase-3 is an apoptosis-specific protease and various apoptotic pathways lead to the proteolytic activation of this protease from its proenzyme form (Kothakota et al., 1997). Following infection with PAK, caspase-3 activity is detected in HeLa cell lysates within 5 h p.i. (Fig. 2) and this activity is blocked by the caspase-3-specific inhibitor DEVD (N-acetyl-Asp-Glu-Val-Asp; BioMol). Fragmentation of DNA, another indicator of the late events of apoptosis, results in the appearance of cells containing subG1 levels of DNA that can be detected by flow cytometry analyses of PI-stained cells (Fraker et al., 1995). By 24 h p.i., $29 \%$ of cells infected with strain PAK are hypodiploid in DNA content (Fig. 3b) whereas subG1 levels of DNA are found in only $5 \%$ of the uninfected control HeLa S3 cells (Fig. 3a). The correlation of apoptosis induction with an increased subG1 cell population is also seen after cells are incubated in the presence of $\mathrm{TNF} \alpha$ and cycloheximide, conditions known to induce apoptosis (Fig. 3d). Interestingly, the subG1 population of PAK-infected cells seemed to be

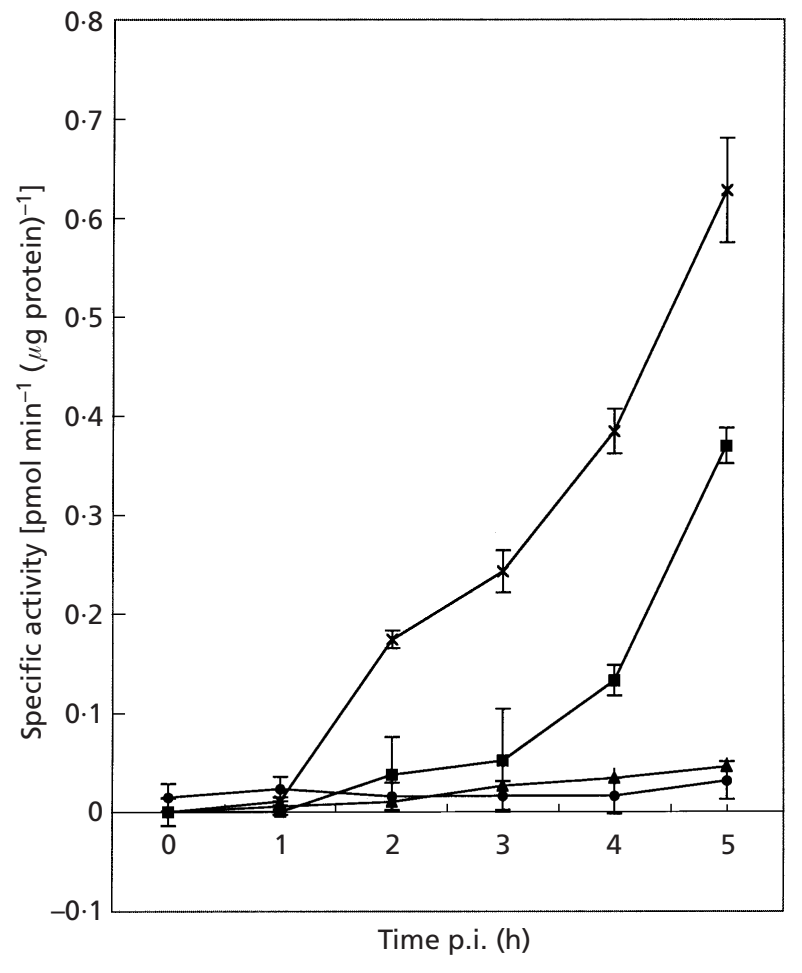

Fig. 2. Induction of caspase-3 activity following infection with $P$. aeruginosa. HeLa cells were infected with either the wildtype PAK ( $\boldsymbol{\square})$ or a type III mutant strain PAKexsA:: $\Omega(\boldsymbol{\Delta})$. Untreated (0) and TNF $\alpha /$ cycloheximide $(\mathbf{x})$ treated cells were used as negative and positive controls, respectively. The means of three independent tests are shown. 


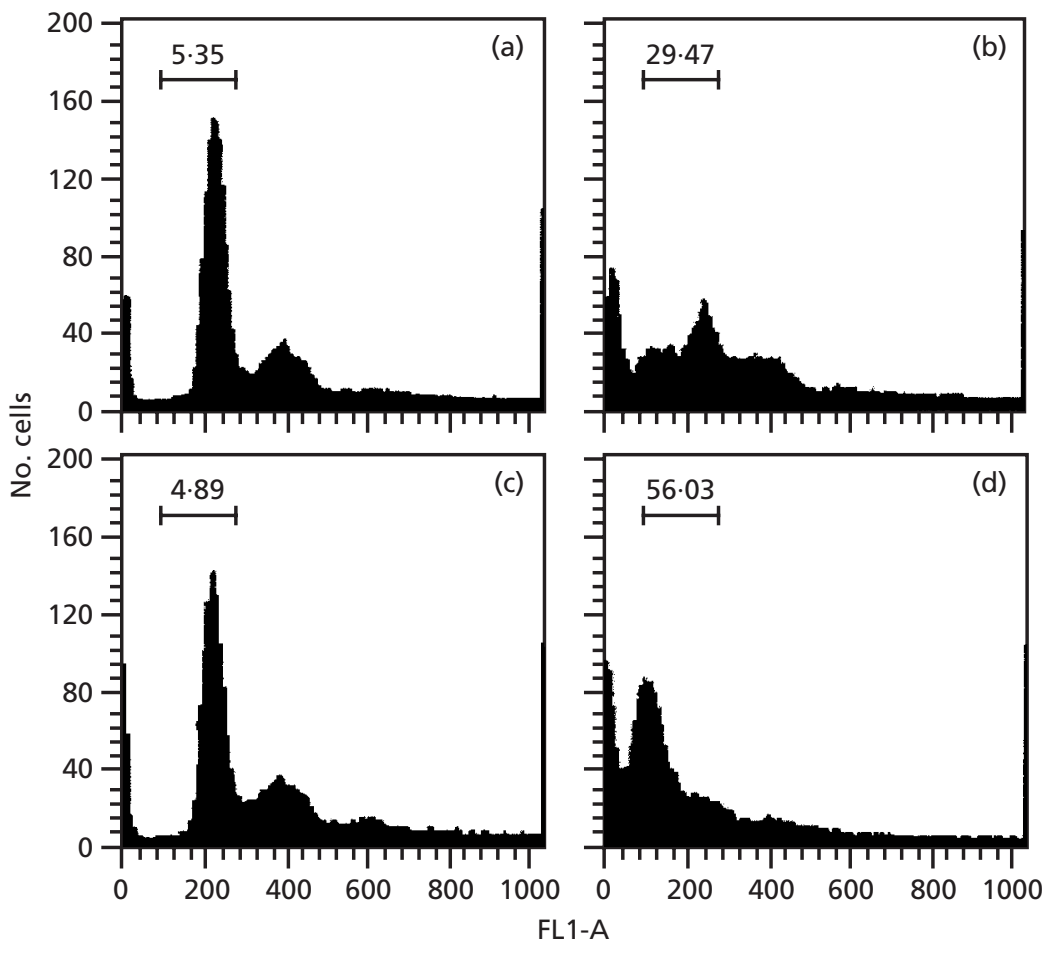

Fig. 3. Histogram of cell number versus $\mathrm{PI}$ uptake to demonstrate DNA fragmentation in HeLa cells. HeLa cells were subjected to the following treatments: (a) uninfected control, (b) infection with wild-type PAK, (c) infection with type III defective mutant PAKexsA:: $\Omega$ and (d) treated with TNF $\alpha /$ cycloheximide. Intensity of fluorescence (FL1-A) was plotted against the number of HeLa cells.

Table 2. Induction of apoptosis by various bacterial strains

ND, Not done; CytoD, cytochalasin $\mathrm{D} ;+$ and - in the table body represent detectable and undetectable changes, respectively.

\begin{tabular}{|c|c|c|c|c|c|c|}
\hline \multirow[t]{3}{*}{ Strain } & \multicolumn{2}{|c|}{ Invasion $(\%)^{*}$} & \multirow{2}{*}{\multicolumn{2}{|c|}{$\begin{array}{l}\text { Apoptotic } \\
\text { morphology } \\
\text { (24 h p.i.) }\end{array}$}} & \multirow{3}{*}{$\begin{array}{l}\text { Caspase-3 } \\
\text { activity } \\
\text { (5 h p.i.) }\end{array}$} & \multirow{3}{*}{$\begin{array}{c}\text { PI uptake (\% } \\
\text { apoptosis) } †\end{array}$} \\
\hline & \multirow[t]{2}{*}{ - CytoD } & \multirow[t]{2}{*}{ + CytoD } & & & & \\
\hline & & & - CytoD & + CytoD & & \\
\hline PAK & $2 \cdot 6$ & $0 \cdot 009$ & + & + & + & 33 \\
\hline PAO1 & $0 \cdot 6$ & $0 \cdot 004$ & + & + & + & $\mathrm{ND}$ \\
\hline 388 & ND & ND & + & + & + & 14 \\
\hline PA103 & 0 & 0 & - & - & - & 4 \\
\hline PAKexsA:: $\Omega$ & $2 \cdot 4$ & $0 \cdot 004$ & - & - & - & 5 \\
\hline
\end{tabular}

* Mean values of three trials.

† Percentage apoptosis was based on subG1 population by FACS analysis.

derived from G1-phase cells, as the appearance of subG1 cells correlated with the loss of an equivalent portion of the G1 population whereas the S+G2 phase cell population remained unchanged (Figs 3 and 6, and data not shown), suggesting that the apoptosis was induced selectively during infection of cells in phase G1 of the cell cycle. In addition, chromatin condensation and marginalization of nuclei was apparent in PAK-infected cells as assessed by staining with the DNA dye Hoechst 33258 (Fig. 1e). These nuclear changes are diagnostic for apoptosis and were consistent with the flow cytometry analyses. Thus, by several criteria, PAK infection rapidly induces apoptosis.

To determine whether PAK-induced apoptosis was a general phenomenon, additional cell lines derived from different lineages were examined. These included canine kidney epithelial cells (MDCK), primary mouse fibroblasts, a human melanoma cell line (MEWO) and breast cancer cell lines (MCF7, HBL100 and MDAMB231), monkey kidney cells (Vero), and a human lung epithelial cell line (A549). PAK-induced morphological changes 
similar to those observed in HeLa S3 cells were seen in MEWO, Vero, mouse fibroblast, MDCK and breast cancer cell lines but not in A549 (data not shown). These results indicate that transformed tumour cell lines as well as non-transformed cell lines undergo apoptosis upon infection by the PAK strain; thus the apoptosis response by mammalian cells upon PAK infection is not unique to the HeLa cell line.

\section{Invasive strains of $\boldsymbol{P}$. aeruginosa are more potent than the cytolytic strain PA103 at triggering apoptosis}

It was noticed in the initial studies that in addition to PAK, the prototypical invasive strain, two other invasive strains (PAO1 and 388) induced consistently high levels of apoptosis. In contrast, in cells infected by the noninvasive, cytolytic strain PA103, apoptotic responses were inapparent or below the detection levels of the assays (Table 2). Although morphological changes were observed within $3 \mathrm{~h}$ p.i., the PA103-infected HeLa cells displayed a classic necrotic morphology, including cell swelling and subsequent lysis (Fig. 1g-i). Furthermore, flow cytometry analysis of PI-stained PA103-infected cells for subG1 DNA levels showed only background levels of DNA fragmentation. Finally, caspase-3 activity, a definitive marker for apoptosis, was absent in PA103infected cells (Table 2). This suggested that apoptosis induction appeared to correlate with the invasive phenotype of the strain.

\section{Induction of apoptosis is independent of bacterial invasion but dependent on the type III secretion machinery}

Because apoptosis induction appeared to correlate with the invasive phenotype of the strain, it was important to determine whether the apoptotic pathway was dependent on bacterial invasion. Thus, gentamicin-exclusion assays were conducted in the presence of the cytoskeletal inhibitor cytochalasin D (Verschueren et al., 1995). As shown in Table 2, cytochalasin D blocked bacterial invasion completely, yet induction of apoptosis continued to occur. Similar results were obtained with genistein (Evans et al., 1998), another inhibitor of bacterial invasion (data not shown). Consistent with its noninvasive phenotype, the cytotoxic strain PA103 could not be recovered from HeLa cells in the invasion assay. Background invasion was determined by infection with the non-invasive E. coli strain SE5000 (Gherardini et al., 1990), which invades at a frequency of $0 \cdot 0008 \%$ in the absence of cytochalasin D or genistein. Thus, induction of apoptosis is independent of invasion.

Although bacterial invasion was not required for apoptosis induction, contact between bacteria and eukaryotic cells, and subsequent expression of the contact-dependent type III secretion system might still be required. ExsA is a global regulator of the type III secretion machinery (Hovey \& Frank, 1995). Examination of monolayer infections with PAK or an isogenic exsA

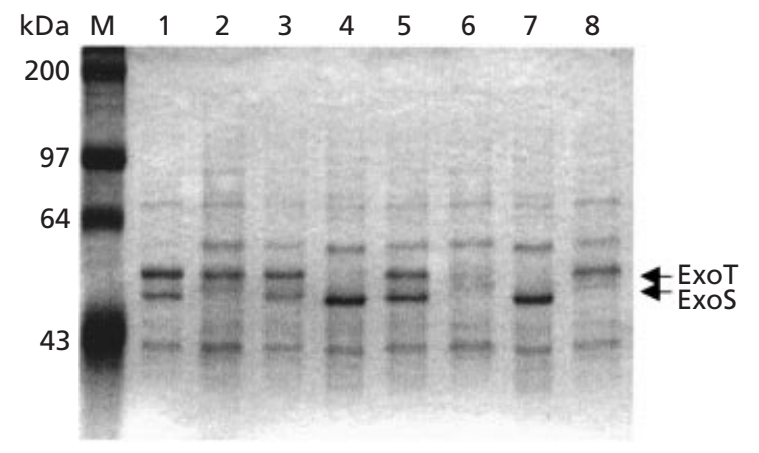

Fig. 4. Secretion of ExoS and ExoT under type III inducing conditions. Secreted proteins in type III inducing medium were separated by $10 \%$ SDS-PAGE and visualized by staining with Coomassie blue. Lane 1, wild-type PAK; lane 2, PAKexoS:: $\Omega$ with vector pDN19; lane 3 , PAKexoS:: $\Omega$ complemented with wild-type exoS clone, pHW9948; lane 4, PAKexoT::Gem with vector pDN18; lane 5, PAKexoT:: Gem complemented with exoT clone, pHW9949; lane 6, PAKexoS:: $\Omega /$ exoT double mutant with vector pDN19; lane 7, PAKexoS:: $\Omega /$ exoT double mutant complemented with exoS clone pHW9948; lane 8, PAKexoS:: $\Omega /$ exoT double mutant complemented with exoT clone pHW9949. M, protein standard marker.

mutant revealed a profound defect in the ability of the type III mutant to provoke apoptosis. Although the invasion frequency for the exs A strain is nearly identical to that of wild-type PAK (Table 2), infection with the exsA-deficient strain fails to induce caspase-3 activity (Fig. 2) and produces a level of DNA fragmentation that is not significantly different from uninfected controls (Fig. 3c). No morphological changes, specifically cell rounding and lifting, were observed in monolayers infected with the exsA mutant even after $24 \mathrm{~h}$. These results demonstrate that the expression of the apoptosisinducing factor is under the control of ExsA, suggesting a type III dependent secreted protein.

\section{ExoS is the apoptotic inducer}

Among the four type III dependent effector molecules known, only exoT is found in both invasive and noninvasive strains of $P$. aeruginosa, whereas exoS and exo $Y$ are specifically encoded by the invasive strains (PAK, PAO1 and 388) and exoU by the cytolytic strains (PA103) (Fleiszig et al., 1997; Yahr et al., 1998). Although all four Exo products were shown to affect host-cell morphology when expressed independently (Vallis et al., 1999), alterations in host cell morphology appear to be predominantly due to the action of ExoS and ExoT (McGuffie et al., 1999; Olson et al., 1999). To test the possible involvement of ExoS and ExoT in the HeLa cell apoptosis, isogenic mutants of exoS, exoT and an exoS exoT double mutant were generated in the PAK background. To confirm that these strains were ExoS and/or ExoT deficient, gene expression in these mutant strains was induced under type III secretion conditions (Yahr et al., 1997). As expected, the mutant strains failed to secrete the corresponding ExoS and/or ExoT proteins as determined by SDS-PAGE (Fig. 4). Apoptotic in- 

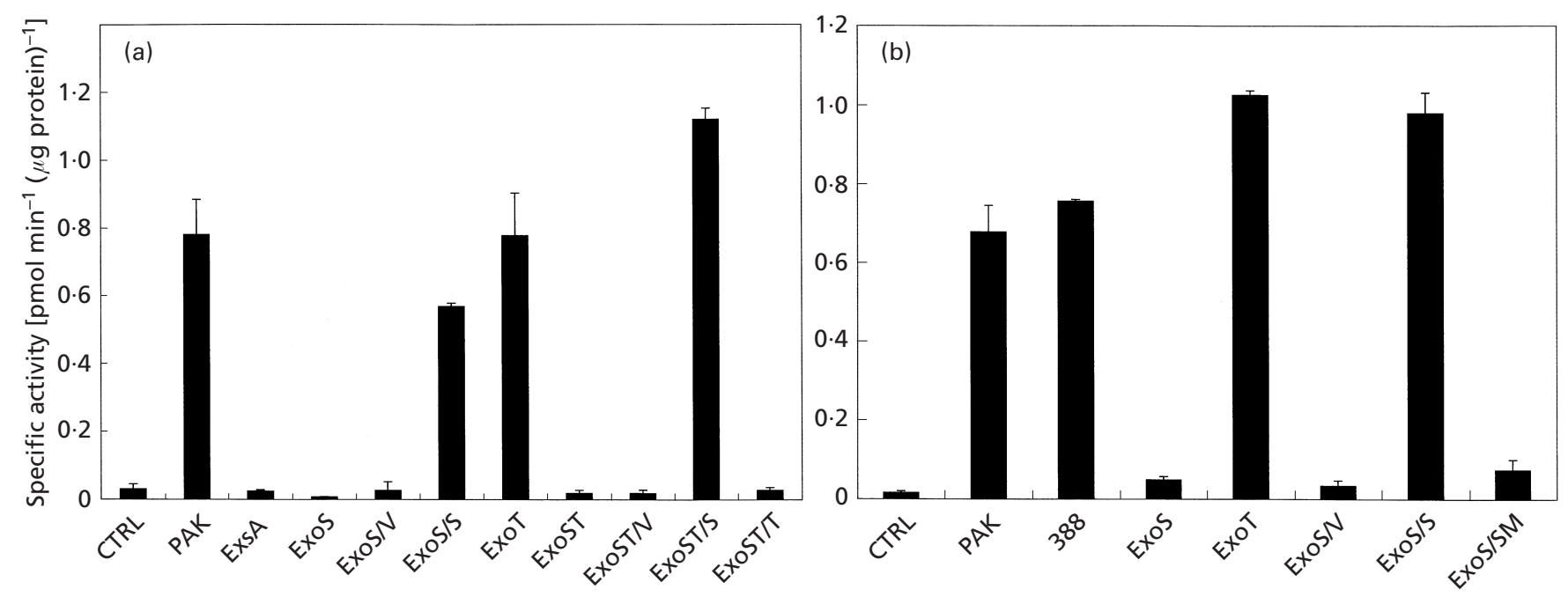

Fig. 5. Induction of caspase- 3 activity following infection with $P$. aeruginosa strains. HeLa cells were infected with $P$. aeruginosa; cell lysates were made at $5 \mathrm{~h} \mathrm{p.i.} \mathrm{and} \mathrm{assayed} \mathrm{for} \mathrm{caspase-} 3$ activity. Assays were done in triplicate and means are shown. (a) Results from cells infected with PAK derivatives. CTRL, uninfected control; PAK, wild-type strain; ExsA, PAKexsA:: $\Omega$; ExoS, PAKexoS:: $\Omega$; ExoS/V, PAKexoS:: $\Omega($ pDN19); ExoS/S, PAKexoS:: $\Omega($ pHW9948); ExoT, PAKexoT::Gem;

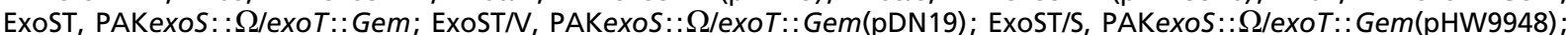
ExoST/T, PAKexoS:: $\Omega /$ exoT::Gem(pHW9949). (b) Results from cells infected with strain 388 derivatives. CTRL, uninfected control; PAK, wild-type strain; 388, wild-type strain; ExoS, 388exoS::Tc; ExoT, 388exoT::Tc; ExoS/N, 388exoS::Tc(pUCPG18); ExoS/S, 388exoS::Tc(pUCPGexoS); ExoS/SM, 388exoS::Tc(pUCPGexoSE381A).

duction was assessed in cells infected with these mutants. Consistent with previous studies with similar mutants in strain 388, both PAKexoS and PAKexoT mutants failed to induce the early cytoskeletal rearrangements that manifest as cell rounding and detachment after infection. However, the PAKexoS/exoT double mutant failed to cause cytoskeletal rearrangement even after $24 \mathrm{~h}$ incubation. Apoptosis in exoT mutant infected cells as determined by caspase-3 activity, DNA fragmentation and chromatin condensation continued unabated at wild-type levels (Fig. 5 and data not shown). These data indicate that ExoT is not an inducer of apoptosis. In contrast, apoptosis was completely abolished in PAKexoS- and PAKexoS/exoT-infected cells. This defect was complemented back to wild-type levels by introduction of an exoS gene clone (pHW9948) but not an exoT gene clone (pHW9949), demonstrating that ExoS is the apoptotic inducer. This was further confirmed by using exoS and exoT mutations in the 388 background. Again, 388exoS::Tc was non-apoptotic while 388exoT::Tc was as potent as wild-type in induction of apoptosis (Fig. 5). The apoptotic potential of the exoS mutant was completely complemented back to the wild-type level by introducing a plasmid containing exoS from 388, pUCPGexoS.

\section{ADP-ribosylating activity of ExoS is essential for apoptosis induction}

Structure-function studies of ExoS have previously shown that this $49 \mathrm{kD}$ protein possesses two distinct functional domains. The $\mathrm{N}$-terminal domain is capable of disrupting the actin cytoskeleton and causing cell rounding through interaction with the host Rho factor, while its C-terminal domain has an ADP-ribosylating activity that is capable of modifying the eukaryotic Ras protein (Pederson et al., 1999). A mutant form of ExoS, ExoSE381A, has a glutamic acid residue changed into alanine at position 381, eliminating the ADP-ribosylase activity (Liu et al., 1996). This mutant form of exoS failed to complement the 388 exos mutant for the apoptosis induction (Fig. 5b). In contrast, this mutant caused significant levels of cell rounding and lifting, indicating effective delivery of the protein. Indeed, this protein is secreted to high levels under type III inducing conditions (data not shown). These data suggest that ADP-ribosylation of a cellular protein by ExoS is required to trigger apoptosis. Importantly, these data also indicate that the changes in cell morphology are likely to be independent of the apoptosis and mediated through a different cellular pathway.

These studies thus far indicate that ExoS is necessary for apoptosis induction but it may not be sufficient. Thus, to determine whether other exotoxins produced by invasive strains might also be required, further complementation studies were performed in the background of PA103. To remove the cytolytic phenotype, a PA103 strain deficient in both ExoU and ExoT production was used. The strain, PA103_exoU/exoT::Tc, is both noncytolytic as described earlier (Vallis et al., 1999) and an apoptotic null strain (Fig. 6). Introduction of a wild-type exoS gene from strain 388, pUCPGexoS, resulted in a strain capable of triggering apoptosis to high levels, 


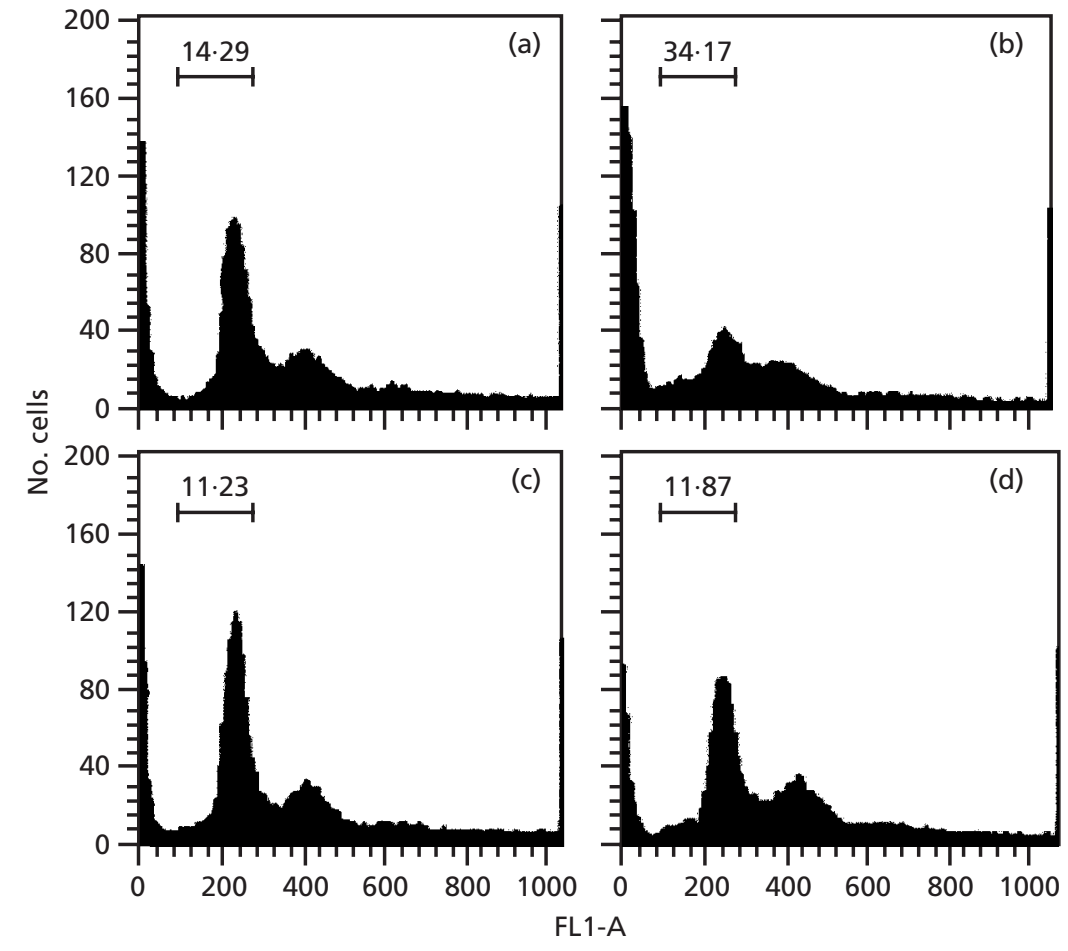

Fig. 6. Flow cytometry analysis following $\mathrm{PI}$ staining of HeLa cells infected with (a) PA103AexoU/exoT::Tc(pUCP18); (b) PA1034 exoU/exoT::Tc(pUCPexoS); (c) PA103 4 exoUI exoT::Tc(pUCPexoSE381A); and (d) PA103 exoU/exoT::Tc(pUCPexoT). The intensity of fluorescence (FL1-A) was plotted against the number of HeLa cells. while introduction of the mutant exoSE381A gene, pUCPGexoSE381A, failed to rescue the apoptosisinducing activity (Fig. 6). These confirm the requirement for the ExoS-mediated ADP-ribosylating activity in triggering apoptosis.

\section{DISCUSSION}

The $P$. aeruginosa ADP-ribosylating toxins ExoS and Exo $T$ play a crucial role in bacterial dissemination to the bloodstream (Frank, 1997). These toxins have also been implicated in alterations of cytoskeletal structure, particularly actin, and signalling via the Ras-dependent pathway in eukaryotic hosts (Frithz-Lindsten et al., 1997). ExoS and ExoT of invasive strains share $75 \%$ amino acid identity, yet ExoT possesses only $0.2 \%$ of the ADP-ribosylating activity of ExoS. A recent report (Hauser \& Engel, 1999) has suggested that $P$. aeruginosa strain PA103 causes a type III secretion dependent apoptosis in macrophages and epithelial cells by a mechanism independent of ExoU. In that study, three criteria were used to evaluate apoptosis: terminal deoxynucleotidyl transferase-mediated dUTP-biotin nick end-labelling assays, cytoplasmic nucleosome assays and Hoeschst staining. Under our assay conditions, PA103 infection failed to induce significant levels of either subG1-like cells or apoptosis-specific caspase-3 activity. Furthermore, an exoU exoT double mutant derivative of PA103 is nonapoptotic, and introduction of an exoS clone into the mutant strain clearly restored the ability to cause HeLa cell apoptosis whereas introduction of an exoT clone resulted in no apoptosis-inducing ability (Fig. 6). However, our data do not rule out the possibility of low-level apoptosis caused by PA103, especially considering the fact that PA103 secrets ExoT, which is highly homologous to ExoS and also has a low ADP-ribosylating activity. It is possible that our assay systems may not be sensitive enough to detect a low level of apoptosis caused by the cytolytic strain PA103.

Previous studies had suggested that apoptosis might be induced by other $P$. aeruginosa gene products. Introduction of purified exotoxin A or porin proteins into mammalian cells has previously been shown to cause apoptosis (Buommino et al., 1999; Hafkemeyer et al., 1999; Morimoto \& Bonavida, 1992). However, the ability of these molecules to induce apoptosis within the context of bacterial infection remains unproven. In addition, it has previously been shown that exotoxin A played no role in the tissue culture and acute infection models (Apodaca et al., 1995). This is consistent with our observation that the exoA mutant strain of PAK is unaltered in its ability to cause apoptosis of HeLa cells (data not shown) and the PA103 strain, which constitutively expresses high level of exotoxin A (Liu, 1966), failed to cause apoptosis.

YopE of Yersinia and SptP of Salmonella are homologues of $P$. aeruginosa ExoS and are also secreted by type III machinery. The homology is limited to the GTPase-activating-protein (GAP) binding domain, which mediates actin disruption, and is not found in the ADP-ribosylating domain (Frithz-Lindsten et al., 1997; Pederson et al., 1999). In addition, SptP has a tyrosine phosphatase domain at the $\mathrm{C}$ terminus while YopE has none. Neither YopE nor SptP have been 
reported to have the apoptotis-inducing phenotype. This is consistent with our observation that it is the ADPribosylating activity unique to ExoS and not the common GAP-binding domain that is responsible for the induction of apoptosis.

A number of other bacterial pathogens are known to cause host cell apoptosis by type III secreted effector molecules. For example, IpaB of Shigella spp. and SipB of Salmonella spp. trigger apoptosis by directly activating caspase-1 (Hilbi et al., 1999; Hersh et al., 1999) while YopJ/P of Yersinia spp. cause apoptosis by inhibiting the NF- $\kappa \mathrm{B}$-mediated pathway (Orth et al., 1999). Similar to these examples, our data suggest $P$. aeruginosa also induces apoptosis by one of its type III secreted proteins. ExoS possesses two functional domains with its $\mathrm{N}$-terminal 234 amino acids capable of causing cell rounding and actin rearrangement in a Rhodependent manner whereas the C-terminal 221 residues have a FAS-dependent ADP-ribosyltransferase activity (Pederson et al., 1999). In addition, it has been demonstrated that exposure to ExoS-producing bacteria, but not non-producing mutants, caused cultured mammalian cells to round up and prevented entry into $\mathrm{S}$ phase (McGuffie et al., 1998). Consistent with this observation, flow cytometry analysis of PI-stained infected cells indicates that $P$. aeruginosa preferentially induced apoptosis in G1-phase cells. It remains to be determined whether the apoptotic phenotype and the ability of ExoS to block the G1/S transition are related.

Caspase-3 activity is detected in cell lysates as early as $5 \mathrm{~h}$ p.i. with PAK. In vivo expression of the type III secretion system is induced and ExoS synthesis is induced only after bacteria-host cell contact. Thus, the interval during which the host cell becomes committed to apoptosis as a result of ExoS function is probably significantly shorter than the $5 \mathrm{~h}$ seen here. This rapidity suggests that ExoS may be acting directly to activate apoptotic pathways in the cell. In vitro, ExoS ADPribosylates several host proteins, including intracellular proteins such as the intermediate filament protein vimentin (Coburn et al., 1989a), several low-molecularmass GTP-binding proteins (Coburn et al., 1989b) and extracellular proteins such as human immunoglobulin 3 and apolipoprotein A1 (Knight \& Barbieri, 1997). In vivo, ExoS has been shown to specifically ADPribosylate Ras proteins, uncoupling Ras-mediated signal-transduction pathways (Vincent et al., 1999, McGuffie et al., 1998; Ganesan et al., 1998, 1999). Among the four Ras proteins (H-Ras, N-Ras, K-RasA and K-RasB), H-Ras was found to be ADP-ribosylated most extensively. Ras is a molecular switch which controls cellular processes in response to extracellular stimuli. GTP-bound forms of Ras can activate downstream effectors (including Raf-1) which initiate MAP kinase pathways that regulate gene expression affecting cellular proliferation, differentiation and apoptosis. Of interest are also the GTPase-activating proteins (GAP), such as Ras-GAP, which accelerate the intrinsic GTPase activity of Ras resulting in inactive GDP-bound forms of Ras (McNeill \& Downward, 1999). Thus, activation of
MAP kinase pathways through ADP-ribosylation of Ras is an attractive mechanistic model for the ExoS-mediated apoptosis. However, the exact pathway(s) by which ExoS triggers apoptosis remains to be elucidated and may involve other yet-to-be-identified cellular targets of the ExoS ADP-ribosyltransferase.

\section{ACKNOWLEDGEMENTS}

We thank Dara Frank for providing strains and making suggestions, K. Gilbert and the Flow Cytometry Resource Center at the University of Arkansas for Medical Sciences for technical assistance and helpful discussions, and Peter Turner for advice on the caspase-3 assays. R. Kurten kindly provided resources for fluorescence microscopy. M.R.K. is supported by the Honour's Research Program of the University of Arkansas College of Medicine. This work was supported by NIH AI39524 (to S. J.), AI42390 and AI22627 (to M.C.).

\section{REFERENCES}

Apodaca, G., Bomsel, M., Lindstedt, R., Engel, J., Frank, D., Mostov, K. E. \& Wiener-Kronish, J. (1995). Characterization of Pseudomonas aeruginosa-induced MDCK cell injury: glycosylation-defective host cells are resistant to bacterial killing. Infect Immun 63, 1541-1551.

Buommino, E., Morelli, F., Metafora, S., Rossano, F., Perfetto, B., Baroni, A. \& Tufano, M. A. (1999). Porin from Pseudomonas aeruginosa induces apoptosis in an epithelial cell line derived from rat seminal vesicles. Infect Immun 67, 4794-4800.

Coburn, J., Dillon, S. T., Iglewski, B. H. \& Gill, D. M. (1989a). Exoenzyme $\mathrm{S}$ of Pseudomonas aeruginosa ADP-ribosylates the intermediate filament protein vimentin. Infect Immun 57, 996-998.

Coburn, J., Wyatt, R. T., Iglewski, B. H. \& Gill, D. M. (1989b). Several GTP-binding proteins, including p21c-H-ras, are preferred substrates of Pseudomonas aeruginosa exoenzyme S. J Biol Chem 264, 9004-9008.

Cowell, B. A., Chen, D. Y., Frank, D. W., Vallis, A. J. \& Fleiszig, S. M. (2000). ExoT of cytotoxic Pseudomonas aeruginosa prevents uptake by corneal epithelial cells. Infect Immun 68, 403-406.

Evans, D. J., Frank, D. W., Finck-Barbancon, V., Wu, C. \& Fleiszig, S. M. (1998). Pseudomonas aeruginosa invasion and cytotoxicity are independent events, both of which involve protein tyrosine kinase activity. Infect Immun 66, 1453-1459.

Finck-Barbancon, V., Goranson, J., Zhu, L., Sawa, T., WienerKronish, J. P., Fleiszig, S. M., Wu, C., Mende-Mueller, L. \& Frank, D. W. (1997). ExoU expression by Pseudomonas aeruginosa correlates with acute cytotoxicity and epithelial injury. Mol Microbiol 25, 547-557.

Fleiszig, S. M., Wiener-Kronish, J.P., Miyazaki, H., Vallas, V., Mostov, K. E., Kanada, D., Sawa, T., Yen, T. S. \& Frank, D. W. (1997). Pseudomonas aeruginosa-mediated cytotoxicity and invasion correlate with distinct genotypes at the loci encoding exoenzyme S. Infect Immun 65, 579-586.

Fraker, P. J., King, L. E., Lill-Elghanian, D. \& Telford, W. G. (1995). Quantification of apoptotic events in pure and heterogeneous populations of cells using the flow cytometer. Methods Cell Biol 46, 57-76.

Frank, D. W. (1997). The exoenzyme $S$ regulon of Pseudomonas aeruginosa. Mol Microbiol 26, 621-629.

Frithz-Lindsten, E., Du, Y., Rosqvist, R. \& Forsberg, A. (1997). 
Intracellular targeting of exoenzyme $\mathrm{S}$ of Pseudomonas aeruginosa via type III dependent translocation induces phagocytosis resistance, cytotoxicity and disruption of actin microfilaments. Mol Microbiol 25, 1125-1139.

Ganesan, A. K., Frank, D. W., Misra, R. P., Schmidt, G. \& Barbieri, J. T. (1998). Pseudomonas aeruginosa exoenzyme $S$ ADPribosylates Ras at multiple sites. J Biol Chem 273, 7332-7337.

Ganesan, A. K., Vincent, T. S., Olson, J. C. \& Barbieri, J. T. (1999). Pseudomonas aeruginosa exoenzyme $\mathrm{S}$ disrupts Ras-mediated signal transduction by inhibiting guanine nucleotide exchange factor-catalyzed nucleotide exchange. $J$ Biol Chem 274, 21823-21829.

Gherardini, F. C., Hobbs, M. M., Stamm, L. V. \& Bassford, P. J., Jr (1990). Complementation of an Escherichia coli proC mutation by a gene cloned from Treponema pallidum. J Bacteriol 172 , 2996-3002.

Hafkemeyer, P., Brinkmann, U., Gottesman, M. M. \& Pastan, I. (1999). Apoptosis induced by Pseudomonas exotoxin: a sensitive and rapid marker for gene delivery in vivo. Hum Gene Ther 10, 923-934.

Hahn, H. P. (1997). The type- 4 pilus is the major virulenceassociated adhesin of Pseudomonas aeruginosa-a review. Gene 192, 99-108.

Hanahan, D. (1983). Studies on transformation of Escherichia coli with plasmids. J Mol Biol 166, 557-580.

Hauser, A. R. \& Engel, J. N. (1999). Pseudomonas aeruginosa induces type-III-secretion-mediated apoptosis of macrophages and epithelial cells. Infect Immun 67, 5530-5537.

Hauser, A. R., Kang, P. J. \& Engel, J. N. (1998). PepA, a secreted protein of Pseudomonas aeruginosa, is necessary for cytotoxicity and virulence. Mol Microbiol 27, 807-818.

Hersh, D., Monack, D. M., Smith, M. R., Ghori, N., Falkow, S. \& Zychlinsky, A. (1999). The Salmonella invasin SipB induces macrophage apoptosis by binding to caspase-1. Proc Natl Acad Sci U S A 96, 2396-2401.

Hilbi, H., Moss, J. E., Hersh, D. \& 7 other authors (1999). Shigellainduced apoptosis is dependent on caspase- 1 which binds to IpaB. J Biol Chem 273, 32895-32900.

Holloway, B. W., Krishnapillai, V. \& Morgan, A. F. (1979). Chromosomal genetics of Pseudomonas. Microbiol Rev 43, 73-102.

Hovey, A. K. \& Frank, D. W. (1995). Analyses of the DNA-binding and transcriptional activation properties of ExsA, the transcriptional activator of the Pseudomonas aeruginosa exoenzyme $\mathrm{S}$ regulon. J Bacteriol 177, 4427-4436.

Iglewski, B. H. \& Kabat, D. (1975). NAD-dependent inhibition of protein synthesis by Pseudomonas aeruginosa toxin. Proc Natl Acad Sci U S A 72, 2284-2288.

Iglewski, B. H., Sadoff, J., Bjorn, M. J. \& Maxwell, E. S. (1978). Pseudomonas aeruginosa exoenzyme $S$ : an adenosine diphosphate ribosyltransferase distinct from toxin A. Proc Natl Acad Sci U S A 75, 3211-3215.

Knight, D. A. \& Barbieri, J. T. (1997). Ecto-ADP-ribosyltransferase activity of Pseudomonas aeruginosa exoenzyme S. Infect Immun 65, 3304-3309.

Kothakota, S., Azuma, T., Reinhard, C. \& 8 other authors (1997). Caspase-3-generated fragment of gelsolin: effector of morphological change in apoptosis. Science 278, 294-298.

Kulich, S. M., Frank, D. W. \& Barbieri, J. T. (1995). Expression of recombinant exoenzyme $\mathrm{S}$ of Pseudomonas aeruginosa. Infect Immun 63, 1-8.
Liu, P. V. (1966). The roles of various fractions of Pseudomonas aeruginosa in its pathogenesis. 3. Identity of the lethal toxins produced in vitro and in vivo. J Infect Dis 116, 481-489.

Liu, S., Kulich, S. M. \& Barbieri, J. T. (1996). Identification of glutamic acid 381 as a candidate active site residue of Pseudomonas aeruginosa exoenzyme S. Biochemistry 35, 2754-2758.

McGuffie, E. M., Frank, D. W., Vincent, T. S. \& Olson, J. C. (1998). Modification of Ras in eukaryotic cells by Pseudomonas aeruginosa exoenzyme S. Infect Immun 66, 2607-2613.

McGuffie, E. M., Fraylick, J. E., Hazen-Martin, D. J., Vincent, T. S. \& Olson, J. C. (1999). Differential sensitivity of human epithelial cells to Pseudomonas aeruginosa exoenzyme S. Infect Immun 67, 3494-3503.

McNeill, H. \& Downward, J. (1999). Apoptosis: Ras to the rescue in the fly eye. Curr Biol 9, R176-R179.

Morimoto, H. \& Bonavida, B. (1992). Diphtheria toxin- and Pseudomonas A toxin-mediated apoptosis: ADP ribosylation of elongation factor-2 is required for DNA fragmentation and cell lysis and synergy with tumour necrosis factor-alpha. J Immunol 149, 2089-2094.

Nunn, D., Bergman, S. \& Lory, S. (1990). Products of three accessory genes, pilB, pilC, and pilD, are required for biogenesis of Pseudomonas aeruginosa pili. J Bacteriol 172, 2911-2919.

Ohman, D. E., Burns, R. P. \& Iglewski, B. H. (1980). Corneal infections in mice with toxin A and elastase mutants of Pseudomonas aeruginosa. J Infect Dis 142, 547-555.

Olson, J. C., Fraylick, J. E., McGuffie, E. M., Dolan, K. M., Yahr, T. L., Frank, D. W. \& Vincent, T. S. (1999). Interruption of multiple cellular processes in HT-29 epithelial cells by Pseudomonas aeruginosa exoenzyme S. Infect Immun 67, 2847-2854.

Orth, K., Palmer, L. E., Bao, Z. Q., Stewart, S., Rudolph, A. E., Bliska, J. B. \& Dixon, J. E. (1999). Inhibition of the mitogenactivated protein kinase kinase superfamily by a Yersinia effector. Science 285, 1920-1923.

Pederson, K. J., Vallis, A. J., Aktories, K., Frank, D. W. \& Barbieri, J. T. (1999). The amino-terminal domain of Pseudomonas aeruginosa ExoS disrupts actin filaments via small-molecularweight GTP-binding proteins. Mol Microbiol 32, 393-401.

Salyers, A. A. \& Whitt, D. D. (1994). Bacterial Pathogenesis: a Molecular Approach. Washington, DC: American Society for Microbiology.

Simpson, D. A., Ramphal, R. \& Lory, S. (1995). Characterization of Pseudomonas aeruginosa fliO, a gene involved in flagellar biosynthesis and adherence. Infect Immun 63, 2950-2957.

Totten, P. A. \& Lory, S. (1990). Characterization of the type a flagellin gene from Pseudomonas aeruginosa PAK. J Bacteriol 172, 7188-7199.

Tummler, B. \& Kiewitz, C. (1999). Cystic fibrosis: an inherited susceptibility to bacterial respiratory infections. Mol Med Today $5,351-358$

Vallis, A. J., Finck-Barbancon, V., Yahr, T. L. \& Frank, D. W. (1999). Biological effects of Pseudomonas aeruginosa type III-secreted proteins on CHO cells. Infect Immun 67, 2040-2044.

Verschueren, H., van der Taelen, I., Dewit, J., De Braekeleer, J., De Baetselier, P., Aktories, K. \& Just, I. (1995). Effects of Clostridium botulinum $\mathrm{C} 2$ toxin and cytochalasin $\mathrm{D}$ on in vitro invasiveness, motility and F-actin content of a murine $\mathrm{T}$ lymphoma cell line. Eur J Cell Biol 66, 335-341.

Vincent, T. S., Fraylick, J. E., McGuffie, E. M. \& Olson, J. C. (1999). ADP-ribosylation of oncogenic Ras proteins by Pseudomonas aeruginosa exoenzyme S in vivo. Mol Microbiol 32, 1054-1064. 
Wall, D. \& Kaiser, D. (1999). Type IV pili and cell motility. Mol Microbiol 32, 1-10.

Yahr, T. L., Goranson, J. \& Frank, D. W. (1996a). Exoenzyme S of Pseudomonas aeruginosa is secreted by a type III pathway. Mol Microbiol 22, 991-1003.

Yahr, T. L., Barbieri, J. T. \& Frank, D. W. (1996b). Genetic relationship between the 53- and 49-kilodalton forms of exoenzyme S from Pseudomonas aeruginosa. J Bacteriol 178, 1412-1419.

Yahr, T. L., Mende-Mueller, L. M., Friese, M. B. \& Frank, D. W.
(1997). Identification of type III secreted products of the Pseudomonas aeruginosa exoenzyme $S$ regulon. J Bacteriol 179, 7165-7168.

Yahr, T. L., Vallis, A. J., Hancock, M. K., Barbieri, J. T. \& Frank, D. W. (1998). ExoY, an adenylate cyclase secreted by the Pseudomonas aeruginosa type III system. Proc Natl Acad Sci U S A 95, 13899-13904.

Received 28 February 2000; revised 17 May 2000; accepted 25 May 2000 